\title{
Finite element method analysis of surface roughness transfer in micro flexible rolling
}

\author{
Feijun $\mathrm{Qu}^{1}$, Haibo $\mathrm{Xie}^{1}$ and Zhengyi Jiang ${ }^{1, a}$ \\ ${ }^{1}$ School of Mechanical, Materials and Mechatronic Engineering, University of Wollongong. Northfields Avenue, Wollongong 2522, \\ Australia
}

\begin{abstract}
Micro flexible rolling aims to fabricate submillimeter thick strips with varying thickness profile, where the surface quality of products is mainly determined by initial workpiece surface roughness and subsequent surface asperity flattening process, which is affected by process parameters during rolling. This paper shows a 3D finite element model for flexible rolling of a $250 \mu \mathrm{m}$ thick workpiece with reduction of 20 to $50 \%$, and rolling phase with thinner thickness indicates a better ability to decrease the surface roughness. Four types of initial workpiece surface roughness are studied in the simulation, and the influences of process parameters, such as friction coefficient, rolling speed and roll gap adjusting speed, on surface asperity flattening of workpieces with different initial surface roughness have been numerically investigated and analysed.
\end{abstract}

\section{Introduction}

Flexible rolling has been rapidly developed and gradually used on a large industrial scale in recent years to meet the rising demand for weight-saving and cost-efficient products as the roll gap may be adjusted to achieve a variable thickness along the metal sheet's length during the rolling process [1]. In the meantime, numerous research activities have been conducted to obtain a better understanding and make further development of this forming technology. Engler et al. [2] presented the process optimisation and control of material properties in the flexible rolling of aluminium alloy sheet based on labscale experiments, which elucidated the range of properties that could be realised through flexible rolling while maintaining reproducible constant material properties. Huang et al. [3] proposed a flexible rolling simulation model on the basis of Deform-3D and verified the feasibility of flexible rolling by comparison between simulation curve and target profile curve. They later discussed the influence of different process parameters on the quality of flexibly rolled products and optimised these parameters to obtain better results via orthogonal trial [4]. Kopp et al. [5] reviewed the flexible rolling process launched at the Institute of Metal Forming and the company Mubea. With a controlled online adjustment of the roll gap, any thickness transitions could be selected and adapted exactly to the demanded load of the product in use. Zhang et al. [6] derived a mathematical formula to control the vertical motion of the roll in flexible rolling, which proved effective by simulation outcomes, and they also found that the vertical velocity of the roll was significantly impacted by the length of the transition zone of flexibly rolled blank and the diameter and rotation speed of the roll. Liu et al. [7-9] set up formulas for calculating parameters, such as roll force, forward slip and horizontal velocity in flexible rolling, and performed finite element simulations and experiments to further verify the theoretical calculations. This technology had proved feasible and would become a new growth point in rolling area.

Additionally, exploration of flexible rolling at the microscale has currently begun to follow the technological development towards miniaturisation of engineering systems and devices. For instance, $\mathrm{Qu}$ et al. $[10,11]$ numerically modelled the flexible rolling process with initial workpiece thickness decreased to the micrometer range. They concentrated on looking into the springback of the workpiece along the thickness direction with consideration of the microstructure of the material. Nonetheless, few papers report the tribological feature as well as surface roughness transfer in this novel rolling technology. Most discussion about these issues has taken place in the field of conventional hot and cold rolling. Jiang et al. [12] established a finite element model to probe the effects of the flow stress of the oxide scale, the friction coefficients at the roll-scale and the scale-steel interfaces, the rolling speed and the temperature on the final surface roughness in hot strip rolling. The simulation results exhibited good agreement with the calculated ones, showing that the developed model was applicable in hot strip mills. Tang et al. [13] also

\footnotetext{
$\overline{\mathrm{a}}$ Corresponding author: jiang@uow.edu.au
} 
simulated the evolution of surface roughness during hot strip rolling with oxide scale. They revealed that both the scale layer thickness and the surface roughness of work roll would affect the final surface roughness significantly, while the impact of asperity wavelength on the final roughness was not significant. Le and Sutcliffe [14] identified the way, in which different wavelengths of roughness behave by analysis of the spectrum of the surface roughness, utilising the fast Fourier transform method and quantified the area of the micro-pits with roll marks subtracted off via a newly developed image analysis technique in cold rolling of aluminium alloy. Some researchers have also studied the surface roughness transfer in the specific case of skin pass rolling. Kijima [15] experimentally and analytically investigated the influence of roll radius on surface roughness transfer in skin pass rolling of steel strip, taking into account the elastic deformation and surface roughness of the roll. The results indicated that the skin pass rolling related to roughened rolls was appropriately simulated with large radius rolls, and the peak pressure from vertical compression was the most significant parameter for roughness transfer under this condition. Afterwards, Kijima [16] conducted experiments to examine the effect of lubrication on surface roughness transfer in skin pass rolling with roughened rolls. It was pointed out that the rolled surface roughness decreased to a larger degree at a larger rolling force with lubrication than that with the dry condition, which was not clearly observed in the case of the small roll due to a short contact length in the roll bite. Kainz et al. [17] investigated and analysed the surface roughness transfer characteristics for both wet and dry skin pass rolling of hot-dip galvanised steel strips by utilising the finite element method. The simulation outcomes clarified that the basic transfer mechanisms of the $3 \mathrm{D}$ elasto-plastic forming processes were a combination of penetration processes and reverse extrusion phenomena. Moreover, the asperity flattening, another major mechanisms of contact interactions in metal forming processes, has been widely studied. Sadowski and Stupkiewicz [18] constituted a micromechanical framework to enquire into the impact of friction on asperity flattening in the presence of bulk deformation. Their findings showed that the friction promoted asperity flattening at high flattening rates, while an anomalous regime existed in which the friction slowed down asperity flattening when the flattening rate was low compared to the bulk deformation rate. Lu et al. [19] did experimental and theoretical work on the asperity flattening process under large bulk strain. They used specimens with two types of model asperities and the results disclosed that the pressure, bulk strain and asperity angles had effects on the asperity flattening and the ridge-shaped asperity exhibited a higher contact ratio than the pyramid-shaped asperity. Sutcliffe [20] analysed the flattening of random rough surfaces on a workpiece undergoing macroscopic deformation with a model of the surface composed of long and short wavelength components, which differed by a factor of 10 . The asperities were found to be flattened at a rate depending on the ratio of the initial root mean square amplitudes of both wavelength components, and the flattening behaviour of the long wavelength asperities became dominant when the amplitude of the long wavelength asperities was much bigger than that of the short wavelength asperities. Consequently, it can be seen from the literatures that the investigation of the surface asperity flattening as well as the evolutionary changes of the surface in the particular case of flexible rolling is still a blank field, particularly when the workpiece is less than a millimeter in thickness.

In this study, a 3D micro flexible rolling finite element model is set up to analyse the surface asperity deformation and the surface roughness transfer of a 250 $\mu \mathrm{m}$ thick workpiece with reductions of 20 to $50 \%$. Four kinds of initial workpiece surface roughness are separately applied to the workpiece, and how the friction coefficient, rolling speed and roll gap adjusting speed influence the final surface roughness are evaluated for each sort of initial surface roughness.

\section{Analysis of surface roughness and deformation of surface asperity}

The actual rough surface of the workpiece is approximated as an ideal rough surface in this investigation, which comprises a series of convex and concave surfaces of identical radii of curvature along rolling direction, as shown in Figure 1.

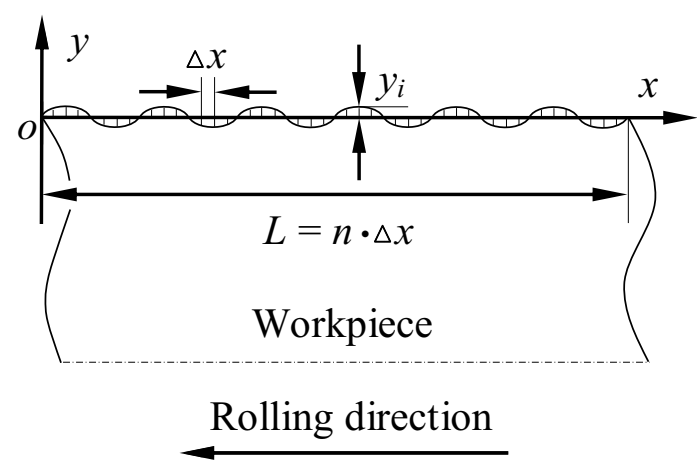

Figure 1. Idealised surface roughness model for the workpiece

Consider the workpiece segment of length $L$, which is divided into $n$ subsegments by $(n-1)$ points evenly spaced on this workpiece segment. The central line average roughness $R_{a}$ may be calculated as [21]:

$$
R_{a}=\frac{1}{n} \sum_{i=1}^{n}\left|y_{i}\right|
$$

where $y_{i}$ is the distance between the curve and the $x$-axis which represents the central line. The $R_{a}$ value can be computed with sufficient accuracy if $n$ is large enough.

Figure 2 illustrates the surface asperity deformation mechanism during micro flexible rolling process. In the interaction between the roll and the workpiece, the roll surface is assumed to be smooth and rigid, and the workpiece asperities are flattened on account of the combined action of normal and tangential contact forces [22], namely both convex and concave surfaces get flatter 
as their radii of curvature become larger, as depicted in Figure 2. The final surface roughness profile depends on all deformations of the asperities in mixed characteristic, i.e. the asperities may be stretched or compressed in disparate directions, and the surface roughness transfer behaviour can be quantitatively estimated by the difference in $R_{a}$ value before and after flexible rolling.

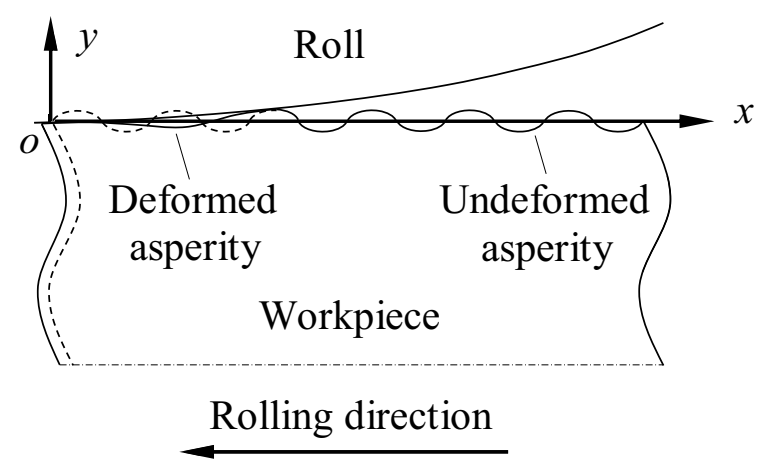

Figure 2. Surface asperity deformation in micro flexible rolling

\section{FEM Simulation conditions}

\subsection{Geometric modelling and mesh generation}

A 3D half model symmetric about the $z-x$ plane has been constructed in ABAQUS/CAE, which consists of the smooth-surfaced upper roll of diameter $4.2 \mathrm{~mm}$ and length $6 \mathrm{~mm}$, and the top half of the rough-surfaced workpiece with dimensions $6.5 \times 1.5 \times 0.25 \mathrm{~mm}$ in the rolling $(x)$, transverse $(z)$ and thickness $(y)$ directions respectively, as displayed in Figure 3.

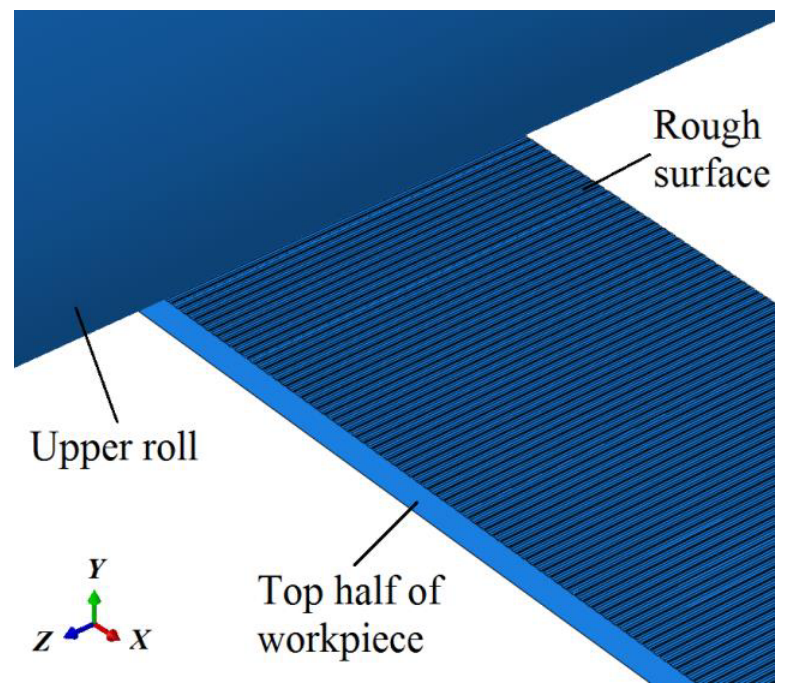

Figure 3. Geometric model of micro flexible rolling considering workpiece surface roughness

The roll was regarded as a rigid body, adopting 4node 3D bilinear rigid quadrilateral elements (R3D4) with uniform mesh size of $0.05 \mathrm{~mm}$, in order to eliminate the effect of its elastic deformation on the deformation pattern of the workpiece asperities. Whereas the workpiece was set as an elastoplastic body and meshed with 10-node modified quadratic tetrahedron elements (C3D10M), as these elements provide a better approximation of the waveform on the workpiece surface, as exposed in Figure 4. The element size of the workpiece matrix was selected to be $0.02 \mathrm{~mm}$, which moderately decreased to a much finer order of $0.005 \mathrm{~mm}$ for the workpiece surface layer, so that penetration can be avoided in the zone of contact between the roll and the workpiece.

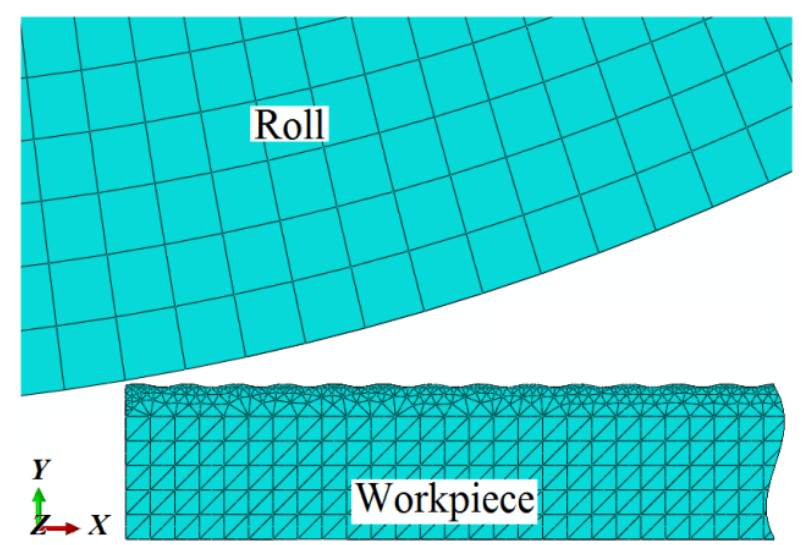

Figure 4. Mesh distributions of the micro flexible rolling model

\subsection{Steps and boundary conditions}

The simulation of micro flexible rolling process employed the implicit method and involved four general, static analysis steps, which are as follows: initial contact, $20 \%$ reduction, thickness transition and $50 \%$ reduction.

At the first stage, the workpiece was made to move in the minus $x$ direction to come into contact with the roll. After that the rolling phase with $20 \%$ reduction began and the workpiece continued forward movement with the aid of friction force between the two objects. When entering the stage of thickness transition, the roll was bestowed with a speed in the minus $y$ direction to obtain the designed profile. This speed was suppressed immediately after reduction of $50 \%$ was reached, which also proclaimed the commencement of the rolling phase with $50 \%$ reduction.

The boundary conditions for each step are listed in Table 1, where $A_{u}$ is the geometric centre of the upper roll, $\alpha$ is the middle surface of the workpiece to the thickness direction, $v_{x}, v_{y}$ and $v_{z}$ are the velocity components in directions $x, y$ and $z$, respectively, $\omega_{x}, \omega_{y}$ and $\omega_{z}$ are the angular velocity components of the roll rotating around the axes $x, y$ and $z$, separately, $\Delta h$ is the reduction amount, $D$ is the diameter of the roll and $l$ is the length of the zone of contact between the roll and the workpiece.

\subsection{Mechanical properties and constitutive model for material}


Table 1. Boundary conditions for different analysis steps

\begin{tabular}{ccl}
\hline Step & Position & Boundary conditions \\
\hline Initial contact & $A_{u}$ & $v_{x}=v_{y}=v_{z}=\omega_{x}=\omega_{y}=0$ \\
& $\alpha$ & $\omega_{z} \neq 0$ \\
& $v_{y}=0$ \\
& $v_{x} \neq 0$ \\
& & $v_{x}=v_{y}=v_{z}=\omega_{x}=\omega_{y}=0$ \\
& $A_{u}$ & $\omega_{z} \neq 0$ \\
& $\alpha$ & $v_{y}=0$ \\
& & $v_{x}=v_{z}=\omega_{x}=\omega_{y}=0$ \\
& & $v_{y}=-\frac{\Delta h \omega_{z} D}{2 l}$ \\
& $A_{u}$ & $\omega_{z} \neq 0$ \\
& & $v_{y}=0$ \\
& $\alpha$ & $v_{x}=v_{y}=v_{z}=\omega_{x}=\omega_{y}=0$ \\
& $A_{u}$ & $\omega_{z} \neq 0$ \\
& $\alpha$ & $v_{y}=0$
\end{tabular}

The workpiece was assigned with mechanical properties of 304 stainless steel including density $(\rho)$, elastic modulus $(E)$, Poisson's ratio $(v)$, initial yield stress $\left(\sigma_{s 0}\right)$ and tangent modulus $\left(E_{T A N}\right)$ at differing strain rates, whose values were originated from Ref. [23] and are given in Table 2.

Table 2. Workpiece mechanical properties: (a) 0.0001/s strain rate; (b) $0.01 / \mathrm{s}$ strain rate; (c) $0.1 / \mathrm{s}$ strain rate

(a)

\begin{tabular}{|c|c|c|c|c|c|}
\hline Material & $\begin{array}{c}\rho \\
\left(\mathrm{kg} / \mathrm{m}^{3}\right) \\
\end{array}$ & $\begin{array}{c}E \\
(\mathrm{GPa})\end{array}$ & $v$ & $\begin{array}{c}\sigma_{s 0} \\
(\mathrm{MPa})\end{array}$ & $\begin{array}{c}E_{T A N} \\
(\mathrm{MPa})\end{array}$ \\
\hline $\begin{array}{c}304 \\
\text { stainless } \\
\text { steel }\end{array}$ & 8000 & 193 & 0.29 & 190 & 1549 \\
\hline \multicolumn{6}{|c|}{ (b) } \\
\hline Material & $\begin{array}{c}\rho \\
\left(\mathrm{kg} / \mathrm{m}^{3}\right) \\
\end{array}$ & $\begin{array}{c}E \\
(\mathrm{GPa}) \\
\end{array}$ & $v$ & $\begin{array}{c}\sigma_{s 0} \\
(\mathrm{MPa})\end{array}$ & $\begin{array}{c}E_{T A N} \\
(\mathrm{MPa})\end{array}$ \\
\hline $\begin{array}{c}304 \\
\text { stainless } \\
\text { steel }\end{array}$ & 8000 & 193 & 0.29 & 205 & 1630 \\
\hline \multicolumn{6}{|c|}{ (c) } \\
\hline Material & $\begin{array}{c}\rho \\
\left(\mathrm{kg} / \mathrm{m}^{3}\right) \\
\end{array}$ & $\begin{array}{c}E \\
(\mathrm{GPa})\end{array}$ & $v$ & $\begin{array}{c}\sigma_{s 0} \\
(\mathrm{MPa})\end{array}$ & $\begin{array}{c}E_{T A N} \\
(\mathrm{MPa})\end{array}$ \\
\hline $\begin{array}{c}304 \\
\text { stainless } \\
\text { steel } \\
\end{array}$ & 8000 & 193 & 0.29 & 215 & 1685 \\
\hline
\end{tabular}

The bilinear true stress-strain constitutive model with isotropic hardening has been utilised to simulate the material behaviour of the workpiece, which is shown in Figure 5 [10]. In regard to isotropic hardening, the yield surface of the von Mises yield condition in stress space grows in size while retaining its shape and position during plastic flow [24].

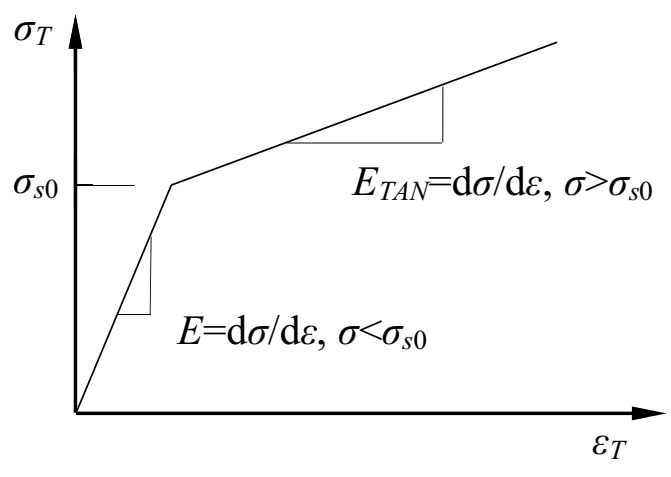

Figure 5. Bilinear isotropic hardening constitutive model for 304 stainless steel

\section{Results and discussion}

Initial surface roughness of $1,2,5$ and $10 \mu \mathrm{m}$, in conjunction with dissimilar rolling parameters, was successively adopted in the simulation to examine their interactive effects on the flattening process of surface asperities. Figure 6 presents the changes of workpiece surface morphology after flexible rolling, where initial surface roughness is $1 \mu \mathrm{m}$, friction coefficient 0.1 , rolling speed $20 \mathrm{~mm} / \mathrm{s}$ and roll gap adjusting speed $2.5 \mathrm{~mm} / \mathrm{s}$, respectively. It is observed that the surface asperities are largely flattened and the final surface profile approaches a smooth line.

In addition, a variety of mesh sizes were individually selected for the surface layer of the workpiece in order to optimise the mesh size, which yields satisfactory computational accuracy with least running time. Table 3 exhibits the influence of mesh size on the computational time and accuracy with other simulation parameters identical to those for Figure 6. As can be seen in Table 3, for either reduction the final surface roughness decreases sharply as the mesh size descends to $5 \mu \mathrm{m}$, and then makes a very slight decrease as the mesh size keeps continually dropping to $2.5 \mu \mathrm{m}$. Although the mesh size 
of $2.5 \mu \mathrm{m}$ seems to be able to obtain more accurate results than other mesh sizes, the computational time soars to $226 \mathrm{~h}$ which is nearly 7 times longer than that for the mesh size of $5 \mu \mathrm{m}$. Based on this evidence, the mesh size of $5 \mu \mathrm{m}$ has been used in the surface layer of the workpiece in the simulation.

Table 3. Influence of mesh size on computational time and accuracy

\begin{tabular}{ccccc}
\hline Mesh size $(\mu \mathrm{m})$ & 20 & 10 & 5 & 2.5 \\
Number of meshes & 8,483 & 12,986 & 30,383 & 140,285 \\
$\begin{array}{c}\text { Computational } \\
\text { time }(\mathrm{h})\end{array}$ & 14 & 21 & 34.5 & 226 \\
$\begin{array}{c}\text { Final surface } \\
\text { roughness for 20\% } \\
\text { reduction }(\mu \mathrm{m}) \\
\quad \text { Final surface }\end{array}$ & 0.684 & 0.639 & 0.603 & 0.601 \\
$\begin{array}{c}\text { roughness for 50\% } \\
\text { reduction }(\mu \mathrm{m})\end{array}$ & 0.597 & 0.562 & 0.548 & 0.547 \\
\hline
\end{tabular}

\subsection{Effect of friction coefficient}

As the friction coefficient usually ranges from 0.1 to 0.3 in cold rolling without lubrication, typical values of 0.1 , 0.2 and 0.3 have been chosen for micro flexible rolling [25]. Figure 7 demonstrates the relationship between the final surface roughness and the friction coefficient for different initial surface roughness with regard to the reductions of 20 and $50 \%$.

It can be seen from Figure 7 that for both reductions, the final surface roughness of the workpiece decreases significantly with an increase of the friction coefficient for each level of initial surface roughness. This is mainly because the friction formulation between the roll and the workpiece employed the penalty method to place constraint to the workpiece [26]. The constraint grows stronger as the friction coefficient turns out to be greater, which leads to a more powerful prevention of workpiece deformation but a quicker occurrence of surface asperity
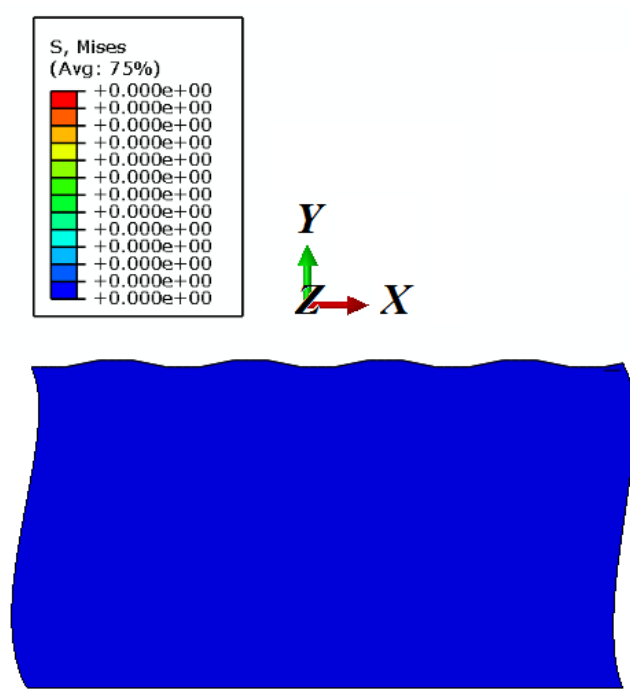
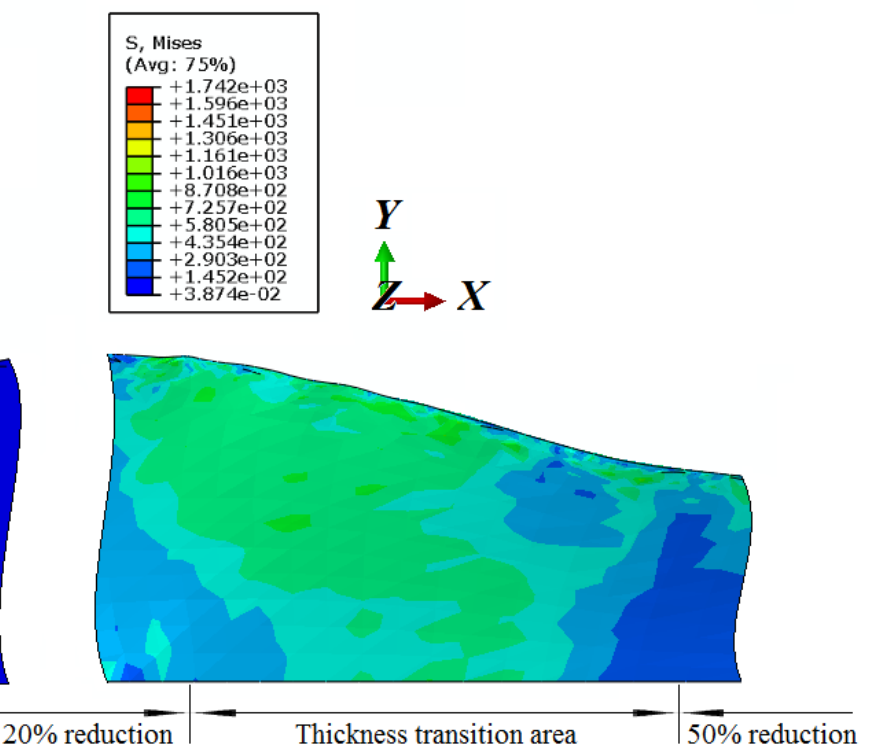

Figure 6. Comparison of workpiece surface morphology before and after flexible rolling

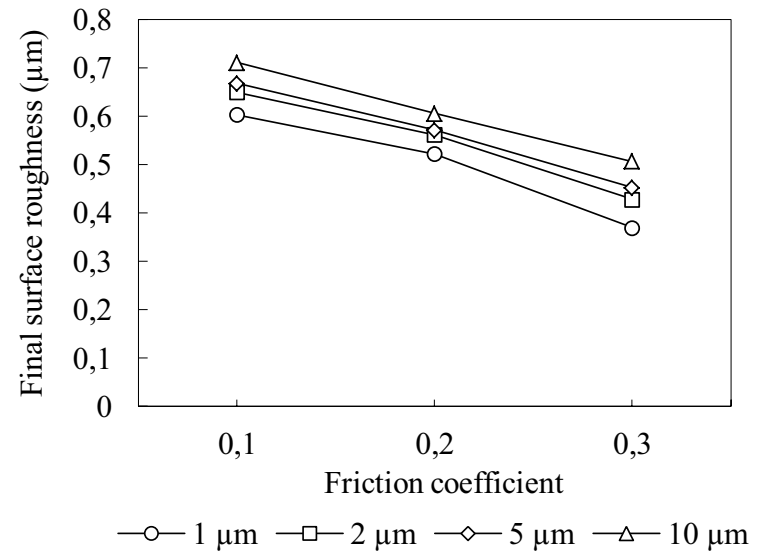

(a)

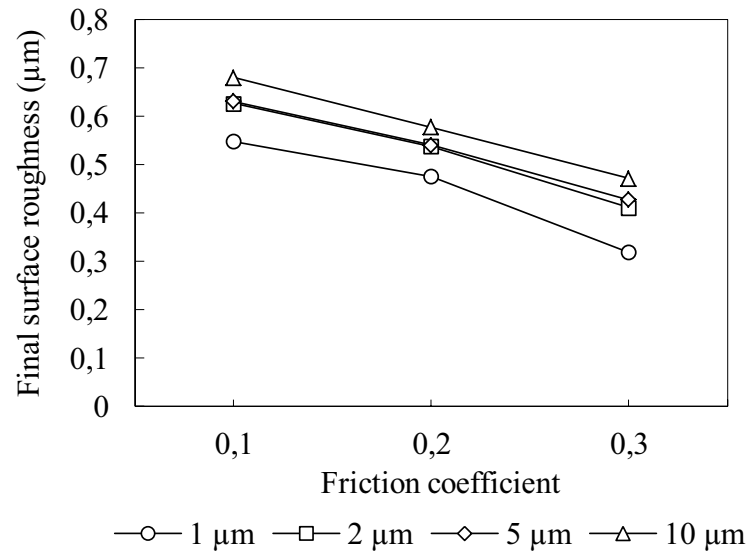

(b)

Figure 7. Final surface roughness versus friction coefficient for different initial surface roughness: (a) $20 \%$ reduction; (b) $50 \%$ reduction 
flattening. Therefore an increasing friction coefficient has an accelerating effect on the surface asperity flattening process.

Table 4 shows the comparison between the simulation and experimental results on the effect of friction coefficient on final surface roughness. The experimental data are approximate values which were originated from Ref. [27], where the initial surface roughness was very close to the value of $0.75 \mu \mathrm{m}$, hence simulations with initial surface roughness of $0.75 \mu \mathrm{m}$ have been performed and the results are utilised in Table 4. It is seen that the simulation results are in agreement with the experimental ones, namely the final surface roughness can be further reduced by increasing the friction coefficient. Another point to be noticed is that the increase in reduction gives a rise to the decrease of the final surface roughness, which is rather obviously reflected in the experimental data.

Table 4. Comparison between simulation and experiment: (a) $20 \%$ reduction; (b) $50 \%$ reduction

(a)

\begin{tabular}{ccc}
\hline \multirow{2}{*}{ Friction coefficient } & \multicolumn{2}{c}{ Final surface roughness $(\mu \mathrm{m})$} \\
\cline { 2 - 3 } & Simulation & Experimental \\
\hline 0.1 & 0.352 & 0.245 \\
0.3 & 0.273 & 0.238 \\
Difference $(\%)$ & 22.44 & 2.86 \\
\hline \multirow{2}{*}{ Friction coefficient } & $(\mathrm{b})$ & \\
\cline { 2 - 3 } & \multicolumn{2}{c}{ Final surface roughness $(\mu \mathrm{m})$} \\
\hline 0.1 & Simulation & Experimental \\
0.3 & 0.226 & 0.101 \\
Difference $(\%)$ & 0.164 & 0.075 \\
& 27.43 & 25.74 \\
\hline
\end{tabular}

The positive effect of friction coefficient on the flattening of surface asperities can also get convinced by Bay et al.'s work [28, 29], where they argued that the real area of contact increased as the surface asperity flattening process was enhanced by the large friction factor. The exemplary simulation results with initial surface roughness of $10 \mu \mathrm{m}$ are displayed in Table 5, together with the experimental data appearing in Ref. [29]. As is seen from Table 5 that the final surface roughness may be decreased with increasing friction coefficient/factor, which results in a bigger real area of contact irrespective of the reduction or normal pressure.

Table 5. Effect of friction coefficient/factor on surface asperity flattening: (a) simulation; (b) experiment

(a)

\begin{tabular}{ccc}
\hline \multirow{2}{*}{ Friction coefficient } & \multicolumn{2}{c}{ Final surface roughness $(\mu \mathrm{m})$} \\
\cline { 2 - 3 } & $20 \%$ reduction & $50 \%$ reduction \\
\hline 0.1 & 0.711 & 0.680 \\
0.3 & 0.507 & 0.471 \\
\hline & $(\mathrm{b})$ & \\
\hline \multirow{3}{*}{ Friction factor } & \multicolumn{2}{c}{ Real area of contact } \\
\cline { 2 - 3 } & 1 unit of normal & 2 units of \\
& pressure & normal pressure \\
\hline 0 & 0.405 & 0.750 \\
$0.3 \sim 0.4$ & 0.495 & 0.850 \\
\hline
\end{tabular}

\subsection{Influence of rolling speed}

The influence of rolling speed on the final surface roughness is shown in Figure 8, where the friction coefficient is 0.1 and roll gap adjusting speed is $2.5 \mathrm{~mm} / \mathrm{s}$ for all cases.

As is noticed in Figure 8, the increase in rolling speed can promote the process of surface asperity flattening and acquire a rolled surface with lower surface roughness, no matter what the original surface roughness of the workpiece and the reduction are. This being the case a higher rolling speed means a higher strain rate, which speeds up the progressive shearing process especially in the surface zone, and the applied stress may rise up to a higher level in the surface area under this condition, which eventually results in a larger amount of surface deformation of the workpiece [30].

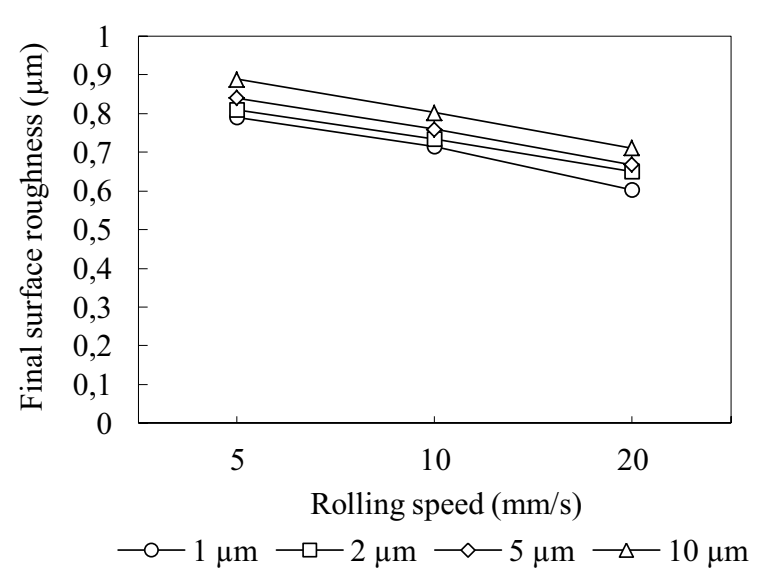

(a)

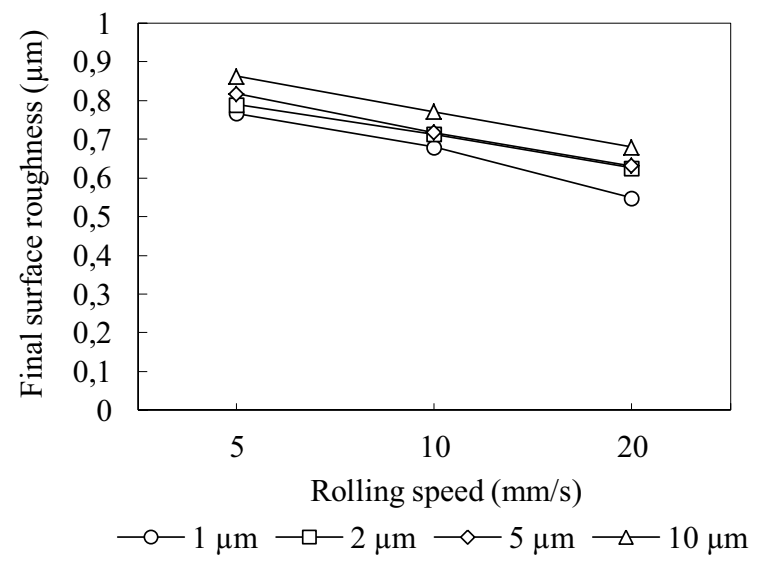

(b)

Figure 8. Final surface roughness versus rolling speed for different initial surface roughness: (a) $20 \%$ reduction; (b) $50 \%$ reduction 


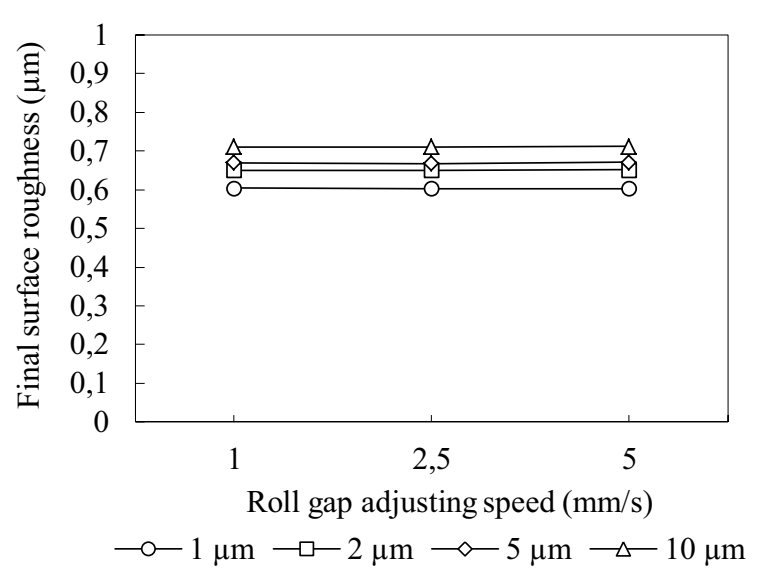

(a)

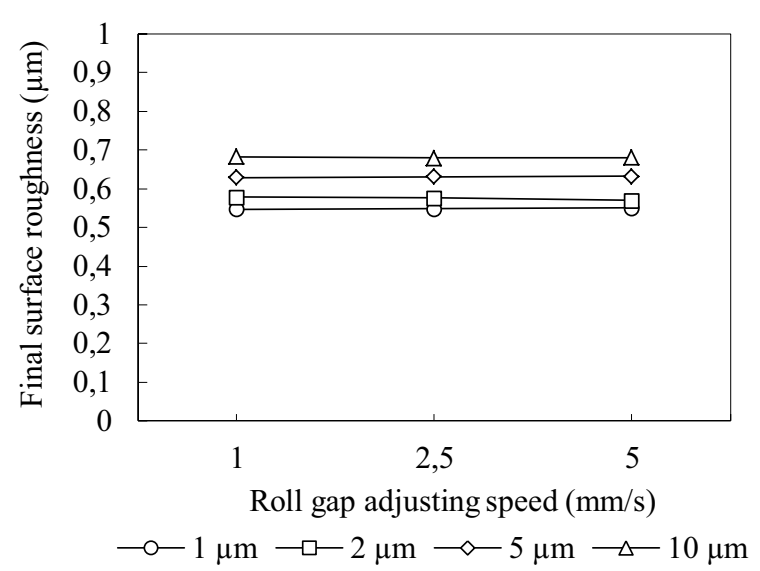

(b)

Figure 9. Final surface roughness versus roll gap adjusting speed for different initial surface roughness: (a) 20\% reduction; (b) 50\% reduction

\subsection{Effect of roll gap adjusting speed}

Figure 9 shows the relationship between the final surface roughness and the roll gap adjusting speed with respect to the same friction coefficient and rolling speed for all instances. As can be noted in Figure 9, the final surface roughness changes little with increasing roll gap adjusting speed, inasmuch as the variation of roll gap adjusting speed alters only the strain rate in the thickness transition area. In other words, the deformation history within the zones of 20 and $50 \%$ reductions hardly changes even though the roll gap adjusting speed varies in different cases. Consequently the roll gap adjusting speed plays an insignificant role in the surface asperity flattening process in the rolling phase with an invariable thickness.

\subsection{Effect of reduction and initial surface roughness}

It can be found out from Figures 7-9 that the final surface roughness decreases with reduction and also reduces considerably as the value of the initial surface roughness falls down. The reason for this phenomenon is that the bigger reduction causes the asperity to be more depressed, thus the contact area between the roll and workpiece surface increases, making the whole surface layer deform more evenly and the rolled surface smoother. According to the same reasoning, the asperities with smaller initial roughness are easier to be flattened and attain a larger contact area during the rolling process, which brings about better surface finish of the rolled workpiece.

\section{Conclusions}

This research analyses the surface roughness transformation in flexible rolling of a $250 \mu \mathrm{m}$ thick workpiece with reduction increasing from 20 to $50 \%$ by finite element modelling. The simulation outcomes can generate the following conclusions:
1. Lower surface roughness can be achieved in the rolling phase with thinner thickness or smaller surface asperity in respect of a constant reduction.

2. The increase of friction coefficient accompanies an obvious acceleration of the surface asperity flattening process.

3. The final surface roughness in the rolling phase with a uniform thickness decreases as the rolling speed increases, but shows little change as the roll gap adjusting speed increases, while a higher roll gap adjusting speed leads to a lower level of final surface roughness in the thickness transition area.

4. The developed finite element model is applicable for investigating the workpiece surface roughness transfer in the longitudinal direction during micro flexible rolling process.

\section{Acknowledgements}

The authors are greatly obliged to University of Wollongong and Australian Research Council (ARC, Grant no. FT120100432) for their support to this study.

\section{References}

1. M. Grüber, R. Kopp, G. Hirt, 60 excellent inventions in metal forming, 213-218 (2015)

2. O. Engler, C. Schäfer, H.-J. Brinkman, J. Brecht, P. Beiter, K. Nijhof, J. Mater. Process. Technol, 229, 139-148 (2016)

3. C. Huang, Y. Gan, J.T. Du, C.Z. Chen, Q.J. Chen, Appl. Mech. Mater, 101-102, 897-900 (2012)

4. J.T. Du, C. Huang, C.Z. Chen, Q.J. Chen, Appl. Mech. Mater, 80-81, 546-550 (2011)

5. R. Kopp, International Sheet Metal Review, 4, 20-24 (2005)

6. Y. Zhang, J. Tan, J. Iron Steel Res. Int, 22(8), 703-708 (2015)

7. X.H. Liu, J. Iron Steel Res. Int, 18(1), 01-07 (2011)

8. G.J. Zhang, X.H. Liu, X.L. Hu, Y. Zhi, J. Iron Steel Res. Int, 20(10), 10-16 (2013)

9. G.J. Zhang, X.H. Liu, Adv. Mat. Res, 418-420, 12321236 (2012) 
10. F.J. Qu, Z.Y. Jiang, H.N. Lu, J. Appl. Math, 2015 (2015)

11. F.J. Qu, Z.Y. Jiang, H.N. Lu, Int. J. Mech. Sci, 105, 182-190 (2016)

12. Z.Y. Jiang, J. Tang, W. Sun, A.K. Tieu, D. Wei, Tribo. Int, 43, 1339-1345 (2010)

13. J.N. Tang, A.K. Tieu, Z.Y. Jiang, Key Eng. Mat, 274276, 499-504 (2004)

14. H.R. Le, M.P.F. Sutcliffe, Wear, 244, 71-78 (2000)

15. H. Kijima, J. Mater. Process. Tech, 214, 1111-1119 (2014)

16. H. Kijima, J. Mater. Process. Tech, 225, 1-8 (2015)

17. A. Kainz, D. Paesold, G. Riha, K. Krimpelstätter, K. Zeman, ABAQUS Austria Users' Coference, (2005)

18. P. Sadowski, S. Stupkiewicz, Tribol. Int, 43, 17351741 (2010)

19. C. Lu, D. Wei, Z. Jiang, K. Tieu, P. I. Mech. Eng. J-J. Eng, 222, 271-278 (2008)

20. M. P. F. Sutcliffe, J. Tribol.-T. ASME, 121, 433-440 (1999)

21. L. Chen, A. Ahadi, J.M. Zhou, J.-E. Ståhl, Modeling and Numerical Simulation of Material Science, 4, 153-162 (2014)

22. S. Stupkiewicz, Z. Mróz, Contact mechanics, 179186 (2002)

23. B. Antoun, J. Korellis, B. Song, Proceedings of the 2007 SEM annual conference on experimental \& applied mechanics, (2005)

24. T.D. Dudderar, J. Duffy, J. Appl. Mech.-T. ASME, 34(1), 200-206 (1967)

25. H.Y. Zhao, PhD. Thesis, (2008)

26. Ö. Yeniay, Mathematical and Computational Applications, 10(1), 45-56 (2005)

27. H.J. Li, PhD. Thesis, (2012)

28. T. Wanheim, N. Bay, A.S. Petersen, Wear, 28, 251258 (1974)

29. N. Bay, T. Wanheim, Wear, 38, 201-209 (1976)

30. H.J. Li, Z.Y. Jiang, D.B. Wei, Wear, 301, 11-18 (2013) 